\title{
African Blackwood (Dalbergia melanoxylon) and Other Local Tanzanian Tree Species' Biological Performance against Subterranean Termites and Wood Decay Fungi
}

Kazushi Nakai ${ }^{\text {a,b,* }}$ and Tsuyoshi Yoshimura ${ }^{b}$

\begin{abstract}
African blackwood (Dalbergia melanoxylon) is known as an indispensable material for the production of musical instruments, e.g., clarinets, oboes, and piccolos. The authors focused on the biological performance of African blackwood and other local Tanzanian species in order to collect preliminary data for developing further uses for these local timbers. Five local species, including African blackwood, were exposed to both subterranean termites (Coptotermes formosanus) and two wood decay fungi (White rot fungus (Trametes versicolor) and Brown rot fungus (Fomitopsis palustris)) according to Japanese standard test methods. African blackwood heartwood had high durability against both termite and fungal attacks, as well as the highest air-dried density of all test species. Some species also indicated a higher durability, even though they had a lower density than African blackwood heartwood. The authors showed the importance of heartwood extractives in terms of biological performance for the local Tanzanian timbers. The authors findings suggested that African blackwood heartwood was clearly useful as a high-durability material in addition to current major applications. The potential of the other local species was also suggested in terms of further timber utilization. These results presented fundamental information about sustainable forest management based on the effective utilization of local timbers.
\end{abstract}

Keywords: Dalbergia melanoxylon; Fabaceae trees; Biological performance; Subterranean termite; Wood decay fungi

Contact information: a: Musical Instruments \& Audio Products Production Unit, Yamaha Corporation, Hamamatsu, Shizuoka 435-8560 Japan; b: Research Institute for Sustainable Humanosphere, Kyoto University, Uji, Kyoto 611-0011 Japan; *Corresponding author: kazushi_nakai@ rish.kyoto-u.ac.jp

\section{INTRODUCTION}

African blackwood (Dalbergia melanoxylon), locally called "Mpingo" in Swahili, is one of the most important trees of the Fabaceae family, due to its value in the musical instrument industry. African blackwood (ABW) is widely distributed among sub-Saharan African countries, including east African countries, such as Tanzania and Mozambique (Sacandé et al. 2007). The tree is also frequently observed in Miombo woodlands, which is a semi-deciduous formation that includes deciduous and evergreen trees and is characterized by an abundance of three genera: Brachystegia, Julbernardia and Isoberlinia (White 1983; Campbell et al. 1996). The general characteristics of the ABW tree have previously been reported as follows: an average height of $5 \mathrm{~m}$ to $7 \mathrm{~m}$; multi-stemmed; and has an irregularly shaped crown (Lovett 1987; Sacandé et al. 2007). In Tanzania, ABW is naturally distributed with population densities of 9 trees/ha to 90 trees/ha and is often grown in clusters (Gregory et al. 1999; Opulukwa et al. 2002; Mariki and Wills 2014; Nakai et al. 2019). Some local community forests in the Kilwa District (Lindi, Tanzania) 
are designated FSC (Forest Stewardship Council) certified forests supported by the local NGO (Non-Government Organization): the MCDI (Mpingo Conservation \& Development Initiative).

The ABW trees co-exist with other local species, e.g., Acacia nigrescens, Afzelia quanzensis, Pterocarpus angolensis, Millettia stuhlmannii, and Combretum spp. (Nakai et al. 2019). Both $A f$. quanzensis and $P$. angolensis grow throughout the deciduous broadleaf savannas and Miombo woodlands in eastern and southern Africa (Cunningham 2016). These wood species have also been regarded as an economically important species for local communities through industrial use as furniture or building materials. Millettia stuhlmannii and Ac. nigrescens are similarly useful as timber materials, both in terms of their color and grain patterns, as well as their wood properties. To conserve a healthy forest, i.e., not only the target species (ABW) but also the surrounding local trees, it must be managed and utilized effectively. Further effective utilization of the local trees is necessary for the sustainable development of local communities.

The heartwood of ABW has been particularly coveted as a material for woodwind instruments, e.g., clarinets, oboes, and piccolos, which is currently its primary use. This is despite the fact that the music instrument industry requires drastically higher quality wood than other industrial timbers. This species tends to present serious problems in terms of wood processing due to lateral twists, deep fluting, and knots, which includes cracks (Lovett 1987). These defects often cause the wood to be rejected from the production process for quality reasons, with an actual timber yield of $9 \%$ in sawmill factories (Gregory et al. 1999). Furthermore, such utilization processes result in intensive harvesting, which can affect the sustainability of the tree resources in a natural forest, due to the long-term growth rate, which takes approximately 70 to $100 \mathrm{y}$ to reach maturity (Jenkins et al. 2002).

The heartwood of ABW is extremely heavy, with an air-dried density of $1.1 \mathrm{~g} / \mathrm{cm}^{3}$ to $1.3 \mathrm{~g} / \mathrm{cm}^{3}$ (Malimbwi et al. 2000; Sprofman et al. 2017). In addition, the heartwood is normally a purplish-black color, which greatly differs from the milky white sapwood. Since both the density and color are likely dependent on the extractives that are synthesized via heartwood formation during the growth periods, they might also have an effect on the physical and chemical properties of ABW. Some extractives from Dalbergia species, e.g., isoflavonoids, neoflavonoids, and other derivatives, have been studied (Donnelly et al. 1975; Martínez-Sotres et al. 2012; Lin et al. 2019). The toxicity or/and repellency properties that heartwood components found in some tropical trees show against termites have also been reported (Santana et al. 2010). In addition, natural resistances to decay and insect attack have been suggested to be dependent on the presence of durable extractives in several tropical species (Usher and Ocloo 1975; Supriana 1988; França et al. 2016; Reis et al. 2017).

The natural resistance of ABW might be a key aspect in terms of understanding the growth traits of high-quality timbers that are relevant to the extractives concentrated during the heartwood formation. However, there is little information about the biological performance of $\mathrm{ABW}$ and other co-existing species that exist in local forests. Species having high biological performance are potentially useful for developing the further timber utilization, which can create the extra benefit through the local forestry. Therefore, the authors' main object in this study was to evaluate the natural resistance of these species to biological attacks. The authors selected local Tanzanian species for the comparative study, so that the results preliminary contribute not only to achieving sustainable forest conservation and management of ABW trees for musical instruments, but to also promote the local community forestry efforts through further utilization. 


\section{EXPERIMENTAL}

\section{Wood Specimens}

Wood specimens were prepared from five Tanzanian local species: Dalbergia melanoxylon (ABW), both heartwood and sapwood; Afzelia quanzensis (AQ), heartwood; Pterocarpus angolensis (PA), heartwood; Millettia stuhlmannii (MS), heartwood; and Xeroderris stuhlmannii (XS), heartwood. These are common species in the Miombo woodlands of the Kilwa District, Lindi, Tanzania. In addition, the sapwood of a Japanese local species, Cryptomeria japonica (CJ), was selected for usage as a control sample (as shown in Table 1) (Ohmura et al. 2011). Due to the original ratio of sapwood found in the ABW logs, the sapwood samples of ABW were prepared with $10 \mathrm{vol} \%$ to $15 \mathrm{vol} \%$ of heartwood. All specimens were cut from air-dried timber that was maintained for longer than 3 months at room temperature. The air-dried weight of each specimen was measured via an electronic scale (GH-252, A\&D Company Ltd., Tokyo, Japan), and the dimensions were measured via a digital caliper (CD-15CP, Mitutoyo Corp, Kawasaki, Japan) in order to calculate the air-dried density before exposure to biological tests.

Table 1. List of the Wood Species Selected for the Comparison Tests and Their Sampled Sections

\begin{tabular}{|c|c|c|c|c|}
\hline \multirow{2}{*}{ Local name } & Scientific name & Family & Sampled Section & Abbreviation \\
\hline \multirow{2}{*}{ Mpingo } & Dalbergia melanoxylon & Fabaceae & Heartwood & ABW-HW \\
\cline { 3 - 5 } & & Sapwood & ABW-SW \\
\hline Mkongo & Afzelia quanzensis & Fabaceae & Heartwood & AQ-HW \\
\hline Pangapanga & Millettia stuhlmannii & Fabaceae & Heartwood & MS-HW \\
\hline Mninga jangwa & Pterocarpus angolensis & Fabaceae & Heartwood & PA-HW \\
\hline Mlondondo & Xeroderris stuhlmannii & Fabaceae & Heartwood & XS-HW \\
\hline \multicolumn{7}{|c|}{ Sugi* } & Cryptomeria japonica & Cupressaceae & Sapwood & CJ-SW \\
\hline * Not a local Tanzanian species but the control species as a reference. \\
\hline \multicolumn{5}{|l}{} \\
\hline \multicolumn{7}{|l}{}
\end{tabular}

\section{Biological Tests}

\section{Termite test}

The termite test was conducted as a no-choice feeding test, according to JIS K 1571:2010 (2010), using the subterranean termite, Coptotermes formosanus. A wood sample measuring $20 \mathrm{~mm}(\mathrm{~L}) \times 10 \mathrm{~mm}(\mathrm{R}) \times 10 \mathrm{~mm}(\mathrm{~T})$, was placed on the plaster bottom of a cylindrical acrylic container $(60 \mathrm{~mm}$ in height and $80 \mathrm{~mm}$ in external diameter) with a plastic sheet. A total of 150 mature $C$. formosanus workers and 15 C. formosanus soldiers were obtained from a laboratory colony maintained in the Deterioration Organisms Laboratory (DOL) at the Research Institute for Sustainable Humanosphere (RISH) at the Kyoto University, and introduced into the test container with 5 replicates for each species. The assembled containers were placed on a water-moistened cotton pad and kept at a temperature of $28 \pm 2{ }^{\circ} \mathrm{C}$ and a relative humidity $(\mathrm{RH})$ greater than $80 \%$ for 3 weeks in the dark. The mass loss of each test specimen was calculated from the difference of the kilndried weights before and after the test at $60 \pm 2{ }^{\circ} \mathrm{C}$ for $48 \mathrm{~h}$. The termite mortality and consumption rates were also calculated after the test period. The wood consumption rate, i.e., the total amount of the sample eaten by an individual worker per day, was determined from the mortality and mass loss, according to the assumption that the mortality of the 
workers developed linearly during the test period. The value was calculated based on the following equation:

$$
\text { Wood Consumption Rate }=\frac{W_{\mathrm{L}} / P / N_{\mathrm{I}}}{\left(P \cdot N_{\mathrm{I}}\right) / \int_{0}^{P}\left[\left(\frac{N_{\mathrm{S}}-N_{\mathrm{I}}}{P}\right) x+N_{\mathrm{I}}\right] \mathrm{d} x}
$$

where $W_{\mathrm{L}}$ is the mass loss of wood specimen, $P$ is the test period, $N_{\mathrm{I}}$ is the number of introduced workers before the test period, and $N_{\mathrm{s}}$ is the number of survived workers. Furthermore, starvation controls were also prepared to discuss toxicity or/and repellency extractives.

\section{Decay test}

The decay test was conducted according to JIS K 1571:2010 (2010), with a specimen size of $10 \mathrm{~mm}(\mathrm{~L}) \times 10 \mathrm{~mm}(\mathrm{R}) \times 20 \mathrm{~mm}(\mathrm{~T})$. Three specimens were exposed to a monoculture of either Trametes versicolor (COV), a white rot fungus, with an accession number of FFPRI 1030, or Fomitopsis palustris (TYP), a brown rot fungus, with an accession number of FFPRI 0507 in a glass jar at a temperature of $26 \pm 2{ }^{\circ} \mathrm{C}$ for 12 weeks in the dark. The accession numbers were associated with the Forestry and Forest Products Research Institute, Tsukuba, Japan. Three decay jars were prepared with 9 replicates for each species. The percent mass loss of each specimen was calculated according to the same procedure described in the termite test.

\section{Statistical Analysis}

The results from the biological tests were compared via the Tukey-Kramer test at $5 \%$ critical difference, in order to analyze the resistance of the samples to each biological attack.

\section{RESULTS AND DISCUSSION}

\section{Air-dried Density of the Wood Specimens}

Table 2 shows the mean air-dried density of each specimen used in the present experiment. The densities of all the Tanzanian species were 2 to 3 times higher than the control specimen, CJ-SW. Of all species samples, ABW-HW had the highest density (ca. $1.3 \mathrm{~g} / \mathrm{cm} 3$ ), with a significant difference from ABW-SW at the $5 \%$ level.

Table 2. Average Air-dried Density of Each Species Before Exposure to the Biological Tests (mean \pm SD)

\begin{tabular}{|c|c|}
\hline Species & $\begin{array}{c}\text { Air-dried Density } \\
\left(\mathrm{g} / \mathrm{cm}^{3}\right)^{*}\end{array}$ \\
\hline ABW-HW & $1.30 \pm 0.01^{\mathrm{a}}$ \\
\hline ABW-SW & $0.96 \pm 0.05^{\mathrm{b}}$ \\
\hline AQ-HW & $0.80 \pm 0.04^{\mathrm{bc}}$ \\
\hline MS-HW & $0.90 \pm 0.04^{\mathrm{bc}}$ \\
\hline PA-HW & $0.90 \pm 0.03^{\mathrm{bc}}$ \\
\hline XS-HW & $0.76 \pm 0.03^{\mathrm{c}}$ \\
\hline CJ-SW & $0.35 \pm 0.02^{\mathrm{d}}$ \\
\hline * Means with the same letter are not significantly different $(p<0.05)$ following one-way \\
ANOVA. $n=14$
\end{tabular}


There was no significant difference between ABW-SW and the other 3 species, AQ-HW ( $p=0.1290)$, MS-HW ( $p=0.9018)$, and PA-HW ( $p=0.8705)$. Furthermore, there was no statistical difference among the other 3 species. In contrast, although the density of XS-HW was relatively lower than the other Tanzanian species, it was also statistically the same as AQ-HW, MS-HW, and PA-HW at 5\% level.

\section{Termite Resistance}

The mortality rates of both the worker and soldier termites after the 3-week forcedfeeding tests are shown in Fig. 1. The mean mortality rates for sample CJ-SW (the control) were $23.5 \%$ for the workers and $46.7 \%$ for the soldiers. The starvation control had a $38.3 \%$ mean mortality rate for the workers and a $100 \%$ mortality rate for the soldiers. The mean mortality rate of the workers for sample $\mathrm{ABW}-\mathrm{HW}$ was $27.1 \%$, which was comparable to sample CJ-SW, but was significantly lower than the starvation control. For sample ABWSW, the $22.9 \%$ mean mortality rate of the workers was not significantly different from sample ABW-HW, but the mortality rate of the soldiers was significantly lower than sample ABW-HW (97.8\% in ABW-HW and 80.0\% in ABW-SW). They were also significantly different from sample CJ-SW $(p<0.05)$. Three heartwood specimens (AQHW, MS-HW, and PA-HW) showed similar mortality rates to the starvation control without significant difference. The mortality rates of heartwood specimen, XS-HW, were statistically equivalent to sample CJ-SW (23.3\% for the workers and $38.7 \%$ for the soldiers).

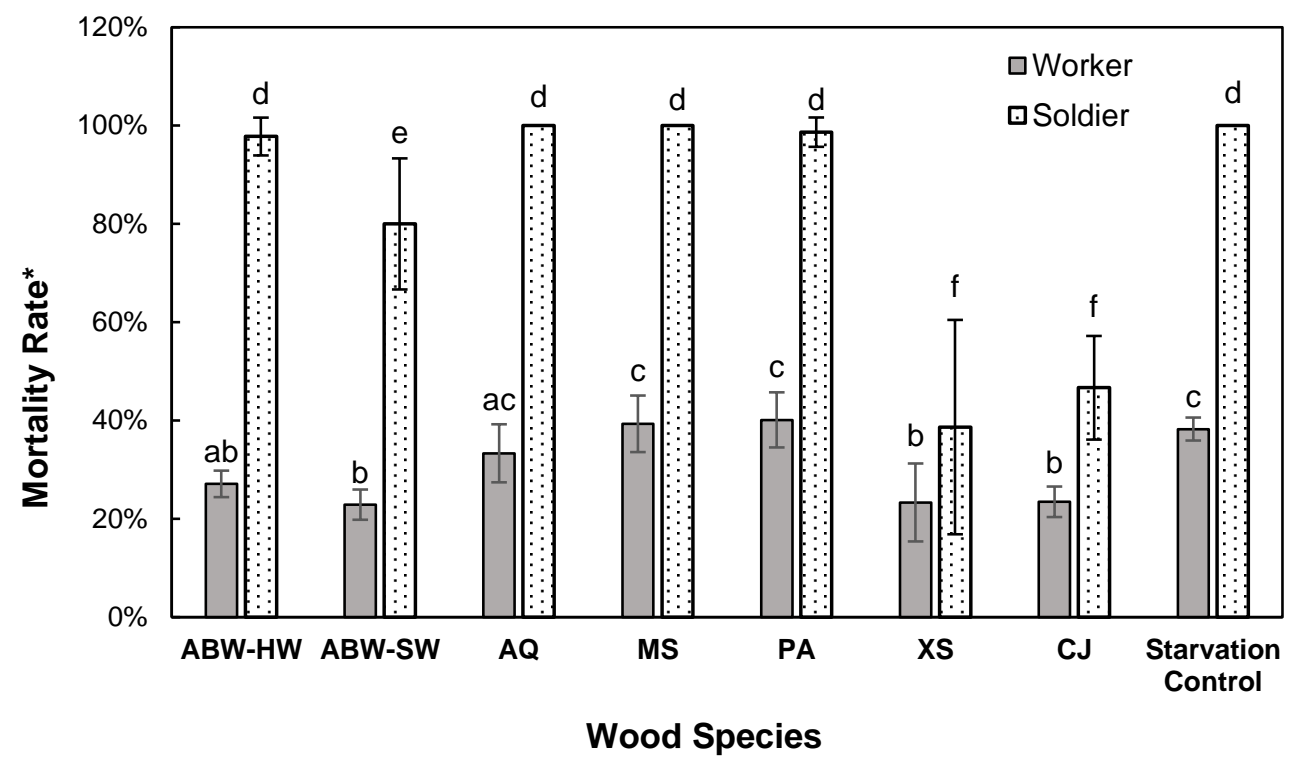

Fig. 1. The mortality rates of the workers and soldiers after the 3-week forced-feeding test with Coptotermes formosanus (mean $\pm S D)(n=5)$. Note: * Means with the same letter are not significantly different $(p<0.05)$ following one-way ANOVA.

Table 3 showed both the mass losses and the wood consumption rates in the termite tests. Sample ABW-HW had a mean mass loss value of $29.7 \mathrm{mg}$, which was significantly different from sample ABW-SW (119.2 mg). This value was statistically similar to the values for samples AQ-HW, MS-HW, and PA-HW ( $p<0.05)$, although sample MS-HW had the lowest mean value among all species $(19.6 \mathrm{mg})$. In contrast, there was no statistical 
difference between sample ABW-SW and sample XS-HW. Regarding the wood consumption rate of each species, a worker consumed $10.7 \mu \mathrm{g} /$ day of sample ABW-HW, which was similar to the rates of samples AQ-HW, MS-HW, and PA-HW. All of the data for sample CJ-SW were significantly different from all the other species at the 5\% level.

Table 3. Mass Loss and Consumption Rate during the Termite Test (mean \pm SD)

\begin{tabular}{|c|c|c|}
\hline Species & $\begin{array}{l}\text { Mass Loss } \\
\quad(\mathrm{mg})^{*}\end{array}$ & $\begin{array}{c}\text { Consumption Rate } \\
(\mu \mathrm{g} / \text { termite/day })^{*}\end{array}$ \\
\hline ABW-HW & $29.67 \pm 5.20^{a}$ & $10.72 \pm 2.02^{d}$ \\
\hline ABW-SW & $119.17 \pm 17.78^{b}$ & $42.73 \pm 6.82^{\mathrm{e}}$ \\
\hline AQ-HW & $48.80 \pm 7.92^{a}$ & $18.57 \pm 2.70^{d}$ \\
\hline MS-HW & $19.60 \pm 4.34^{a}$ & $7.73 \pm 1.54^{d}$ \\
\hline PA-HW & $29.20 \pm 5.40^{a}$ & $11.56 \pm 1.83^{d}$ \\
\hline XS-HW & $128.40 \pm 49.39^{b}$ & $45.64 \pm 15.86^{e}$ \\
\hline CJ-SW & $177.80 \pm 43.24^{c}$ & $63.82 \pm 15.07^{f}$ \\
\hline
\end{tabular}

The mortality rate of the workers for sample ABW-HW was significantly lower than the rates of samples MS-HW, PA-HW, and the starvation control (as shown in Fig. 1). However, the consumption rate of sample ABW-HW was statistically equivalent to the rates of samples MS-HW and PA-HW (as shown in Table 3). It has been suggested that the resistance of wood to termite attacks can be attributed to the density of the wood specimens, which is generally related to wood hardness (Acanakwo et al. 2019). The authors confirmed in this study that the low-density species (samples ABW-SW and XSHW) yielded a higher total mass loss over the high-density species (samples ABW-HW, AQ-HW, MS-HW, and PA-HW) when subjected to termite attacks (as shown in Table 2 and Table 3). Although the air-dried density of sample ABW-SW was approximately 0.96 $\mathrm{g} / \mathrm{cm}^{3}$ in this study (as shown in Table 2), due to the heartwood portion mentioned above, the density of ABW-SW had been previously been reported by Malimbwi et al. (2000) as ca. $0.75 \mathrm{~g} / \mathrm{cm}^{3}$, which was comparable to the XS-HW specimens. The heartwood of Xeroderris stuhlmannii is susceptible to insect attack, especially from powder-post beetles (Lemmens 2007). Since worker termites primarily attacked the sapwood portion of the ABW-SW sample in the test, both the mass loss and the consumption rate for the ABWSW sample was not different from the low-density wood species, which included the CJSW sample, despite its higher density (Table 3).

The density of sample ABW-HW $\left(1.30 \mathrm{~g} / \mathrm{cm}^{3}\right)$ was much higher than the other species samples (Table 2); however, the mortality rate of the workers was significantly lower than the mortality rate in samples MS-HW, PA-HW, and the starvation control (Fig. 1). The value was also statistically equivalent to samples ABW-SW, XS-HW, and CJ-SW, but the mortality rate of the soldiers was significantly higher (Fig. 1). Workers generally provide nutrition to the soldiers; thus, the difference in soldier mortality rates could indicate a difference in the feeding activities of the workers. Since the mortality rates of the workers and the soldiers in samples MS-HW, PA-HW, and AQ-HW were similar to the mortality rates of the starvation control (Fig. 1), it was likely that termite feeding activities against these species was low. The feeding mass of sample ABW-HW did not differ from the 
feeding mass in the other wood species (Table 3). These results suggested that other factors, e.g., the wood extractives, played a role in the biological performance of the tested wood samples.

The biological activity of various wood extractives had been previously reported (Ohmura et al. 2000; Mburu et al. 2007; Borges et al. 2008; Tascioglu et al. 2013). In particular, the high anti-feedant effects of some flavonoids, which included taxifolin and quercetin, against $C$. formosanus had been demonstrated (Ohmura et al. 2000). Other flavonoids, e.g., polyphenols, isoflavonoids, and neoflavonoids, had also been obtained from Fabaceae trees, which included the Dalbergia and Pterocarpus species (Seshadri 1972; Sekine et al. 2009; Yin et al. 2018), and their resistance against termites and fungi had been determined with laboratory tests (Sekine et al. 2009). Considering these facts, the higher mortality rates of the MS-HW and PA-HW samples could be dependent on the presence of these extractives.

\section{Decay Resistance}

Figure 2 showed the percent mass losses of the wood species after exposure to COV and TYP for 12 weeks. The mass loss values of sample ABW-HW, after exposure to both fungi, were the lowest among all tested species, and the mass loss values of samples MSHW and PA-HW were also lower compared to other tested species. The mass loss caused by COV in sample ABW-SW was significantly higher than the mass loss in samples ABWHW and MS-HW, but it was not significantly different from samples AQ-HW and PA-HW. In the case of TYP, the mass loss values of samples ABW-HW and MS-HW were the lowest among all tested species, although they were not statistically different from samples ABW-SW, AQ-HW, and PA-HW. In contrast, the mean mass loss values of sample XSHW were significantly higher than those of other tested Tanzanian species $(20.8 \%$ in COV and $34.4 \%$ in TYP on average) but were similar to the mean mass loss values of sample $\mathrm{CJ}-\mathrm{SW}$ in TYP at a $5 \%$ level.

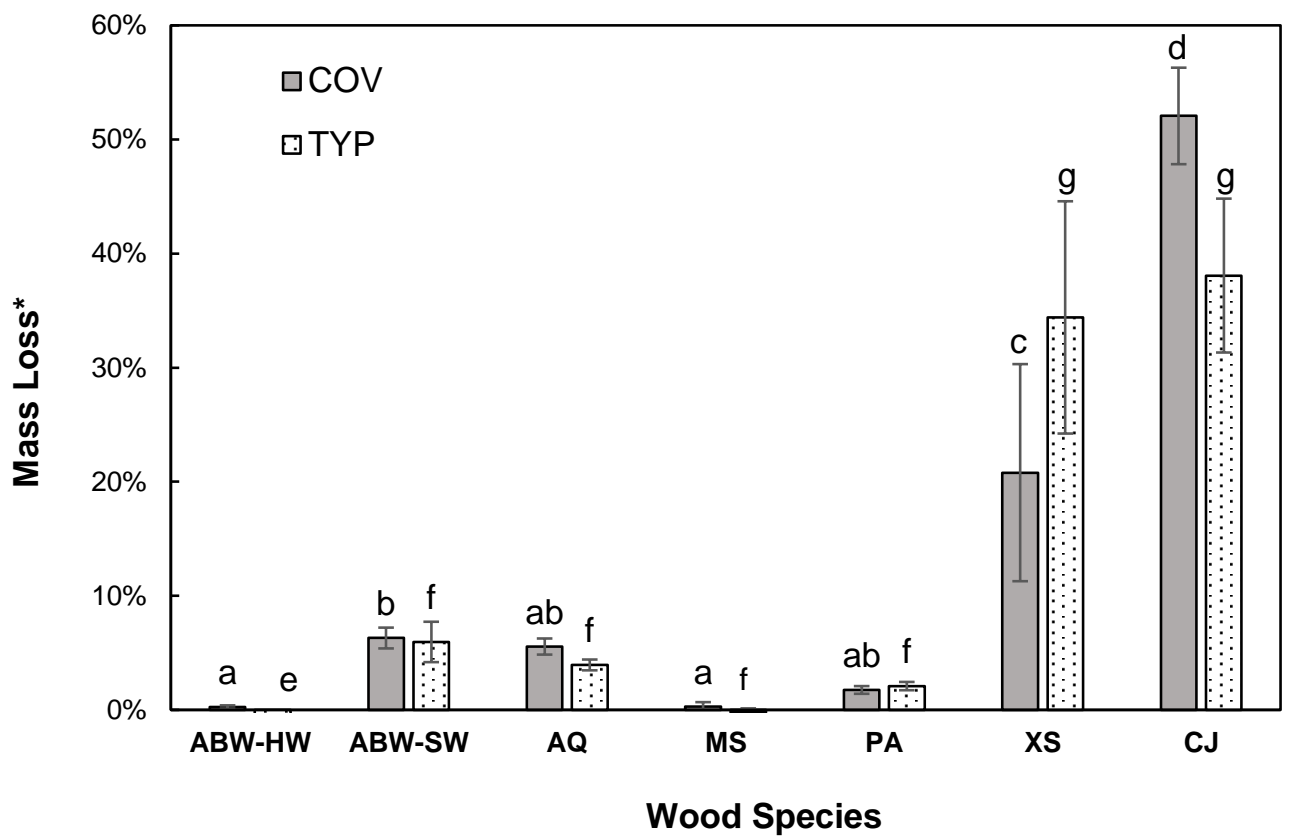

Fig. 2. Mass loss percentages of the tested wood specimens after 12-week exposure to COV and 
TYP (mean \pm SD) $(n=9) .{ }^{*}$ Means with the same letter are not significantly different $(p<0.05)$ following one-way ANOVA.

According to the results of the decay tests, the authors concluded that the decay resistance of the tested wood specimens could be similarly attributed to both wood properties, i.e., the density and the extractives. It was reported that higher density wood species typically decayed more slowly than lower density species (Chambers et al. 2000). It had been suggested that the influence of the heartwood extractives on the durability of the wood went beyond their fungicidal properties. The possible functions of the extractives against fungal colonization included an antioxidant effect (Schultz and Nicholas 2000). Some extractives found in samples ABW-HW, MS-HW, and PA-HW could strongly affect their durability against decay fungi.

\section{Biological Performance of the Test Species}

Consequently, the authors found high biological performance in the heartwood of African blackwood (Dalbergia melanoxylon), while the sapwood was significantly less resistant to termite and fungal attack. The performance of ABW-HW was relatively superior to the other Tanzanian wood species, which could be strongly related to the high concentration of extractives found in the wood. Since the volume percentage of heartwood in the ABW logs had been estimated at over $80 \%$, the durability of the heartwood made a large contribution to the natural biological resistance of this species (Malimbwi et al. 2000).

The extractives found in ABW-HW were reported to be different from those of other Dalbergia species, as well as at higher concentrations, which would contribute to the advantages of ABW as a material (Yin et al. 2018). The flavonoids including neoflavonoids, e.g., melanoxin, have been previously isolated from the extractives of ABW heartwood (Donnelly et al. 1969; Donnelly and O'reilly 1975), and Amri and Juma (2016) confirmed the antimicrobial potential of the extractives from the stem bark of ABW with the presence of flavonoids. In addition, the heartwood of both Pterocarpus angolensis (PA) and Millettia stuhlmannii (MS) showed a higher level of termite resistance than ABW-HW displayed. These woods are widely utilized for construction or furniture in African countries, e.g., Tanzania and Mozambique. Afzelia quanzensis (AQ) is also commercially harvested and utilized in these countries (Cunningham 2016). The authors findings suggested that such local timbers could be further utilized and applied to a broad range of global demands, particularly MS and PA, as materials for situations requiring high durability, e.g., for exterior products.

The construction of a sustainable forestry system based on the local community is a key concept for the future of forestry. Useful trees, such as ABW, are now becoming the main sources of profit in local forestry, in addition to the current charcoal and fuel-wood production (Miya et al. 2012). Therefore, the cultivation of high-quality trees that can meet the present market demand is necessary to achieve a sustainable forest. To cultivate such valuable trees, co-existing trees should be systematically harvested together with the target trees under a sustainable forestry system. Furthermore, the timbers also should be utilized efficiently to improve the timber yield. In this study's findings, the authors showed the potential of Tanzanian local species, including the ABW tree as well as other co-existing trees, to support the local community via sustainable forestry. 


\section{CONCLUSIONS}

1. The heartwood of African blackwood (Dalbergia melanoxylon) was shown to have strong biological performance, whereas the sapwood was remarkably less resistant to termite and fungal attack. The results suggested that ABW-HW was clearly useful as a high-durability material, e.g., as an exterior material, in addition to its current major applications.

2. Wood density was strongly related to the biological performance. The high-density species showed a higher durability than the low-density species. Furthermore, the contribution of heartwood extractives to the durability of the test species was also suggested through the biological tests.

3. The heartwood of Millettia sthulmannii and Pterocarpus angolensis showed a higher biological performance than the heartwood of D. melanoxylon. The high biological performance of other Tanzanian species could be useful for developing the further timber utilization in the local community forestry.

\section{ACKNOWLEDGMENTS}

This work was supported as a part of a joint study for the fundamental studies on achieving sustainable forest utilization focusing on African blackwood (Dalbergia melanoxylon) by the Yamaha Corporation, the Research Institute for Sustainable Humanosphere at Kyoto University, and the Graduate School of Agriculture at Kyoto University.

The authors would like to thank Makala Jasper, Jonas Timothy, Joseph Protas, and the Mpingo Conservation \& Development Initiative in Tanzania for helping the authors gain an understanding of local forests. The authors would also like to thank Neil Bridgland, James Laizer, the Sound \& Fair Ltd. in Tanzania, as well as Motoki Takata, Yoshiyuki Kashima, and the Yamaha Corporation for collecting samples. The author's appreciation also goes to all the Tanzanian local villagers for their kind support.

\section{REFERENCES CITED}

Amri, E., and Juma S. (2016). "Evaluation of antimicrobial activity and qualitative phytochemical screening of solvent extracts of Dalbergia melanoxylon (Guill. \& Perr.)," International Journal of Current Microbiology and Applied Sciences 5(7), 412-423. DOI: 10.20546/ijcmas.2016.507.045

Acanakwo, E. F., Sheil. D., and Moe, S. R. (2019). "Wood decomposition is more rapid on than off termite mounds in an African savanna," Ecosphere 10(1), 1-11. DOI: $10.1002 /$ ecs 2.2554

Borges, L. M. S., Cragg, S. M., Bergot, J., Williams, J. R., Shayler, B., and Sawyer, G. S. (2008). "Laboratory screening of tropical hardwoods for natural resistance to the marine borer Limnoria quadripunctata: The role of leachable and non-leachable factors," Holzforschung 62(1), 99-111. DOI: 10.1515/HF.2008.015

Campbell, B., Frost, P., and Byron, N. (1996). "Miombo woodlands and their use: Overview and key issues," in: The Miombo in Transition: Woodlands and Welfare in 
Africa, B. Campbell (ed.), Center for International Forestry Research (CIFOR), Bogor, Indonesia, pp. 1-10.

Chambers, J. Q., Higuchi, N., Schimel, J. P., Ferreira, L. V., and Melack, J. M. (2000). "Decomposition and carbon cycling of dead trees in tropical forests of the central Amazon," Oecologia 122(3), 380-388. DOI: 10.1007/s004420050044

Cunningham, A. B. (2016). "Trade study of selected east African timber production species," in: Proceedings of the Convention on International Trade in Endangered Species of Wild Fauna and Flora Seventeenth Meeting of the Conference of the Parties, Johannesburg, South Africa. pp. 27-66.

Donnelly, B. J., Donnelly, D. M. X., O’Sullivan, A. M., and Prendergast, J. P. (1969). "Dalbergia species VII, Isolation and structure of melanoxin a new dihydrobenzofuran from Dalbergia melanoxylon Guill. and Perr. (Leguminoseae)," Tetrahedron 25(18), 4409-4414. DOI:10.1016/S0040-4020(01)82981-1

Donnelly, D. M. X., O'Reilly, J., and Whalley, W. B. (1975). "Neoflavanoids of Dalbergia melanoxylon," Phytochemistry 14(10), 2287-2290. DOI: 10.1016/S00319422(00)91118-X

França, T. S. F. A., França, F. J. N., Arango, R. A., Woodward, B. M., and Arantes, M. D. C. (2016). "Natural resistance of plantation grown African mahogany (Khaya ivorensis and Khaya senegalensis) from Brazil to wood-rot fungi and subterranean termites," International Biodeterioration \& Biodegradation 107, 88-91. DOI: 10.1016/j.ibiod.2015.11.009

Gregory, A.-M., Ball, S. M. J., and Eziefula, U. E. (1999). Tanzanian Mpingo 98 Full Report, Mpingo Conservation Project, Kilwa, Lindi, Tanzania.

Jenkins, M., Oldfield, S., and Aylett, T. (2002). International Trade in African Blackwood, Fauna \& Flora International, Cambridge, UK.

JIS K 1571:2010 (2010). "Wood preservatives - Performance requirements and their test methods for determining effectiveness," Japanese Industrial Standards Committee, Tokyo, Japan.

Lemmens, R. H. M. J. (2007). "Xeroderris stuhlmannii (PROTA)," (https://uses.plantnetproject.org/en/Xeroderris_stuhlmannii_(PROTA)), Accessed 8 October 2019.

Lin, S., Liu, R.-H., Ma, G.-Q., Mei, D.-Y., Shao, F., and Chen, L.-Y. (2019). "Two new compounds from the heartwood of Dalbergia melanoxylon," Natural Product Research, 1-8. DOI: 10.1080/14786419.2019.1591397

Lovett, J. (1987). "Mpingo - the African blackwood," Swara 10, 27-28.

Malimbwi, R. E., Luoga, E. J., Hofstad, O., Mugasha, A. G., and Valen, J. S. (2000). "Prevalence and standing volume of Dalbergia melanoxylon in coastal and inland sites of southern Tanzania," Journal of Tropical Forest Science 12(2), 336-347.

Mariki, A. S., and Wills, A. R. (2014). Environmental Factors Affecting Timber Quality of African Blackwood (Dalbergia melanoxylon), Mpingo Conservation \& Development Initiative, Lindi, Tanzania.

Martínez-Sotres, C., López-Albarrán, P., Cruz-de-León, J., García-Moreno, T., RutiagaQuiñones, J. G., Vázquez-Marrufo, G., Tamariz-Mascarúa, J., Herrera-Bucio, R. and (2012). "Medicarpin, an antifungal compound identified in hexane extract of Dalbergia congestiflora Pittier heartwood," International Biodeterioration \& Biodegradation 69, 38-40. DOI: 10.1016/j.ibiod.2011.11.016

Mburu, F., Dumarçay, S., and Gérardin, P. (2007). "Evidence of fungicidal and termicidal properties of Prunus africana heartwood extractives," Holzforschung 61(3), 323-325. DOI: 10.1515/HF.2007.043 
Miya, M., Ball, S. M. J., and Nelson, F. D. (2012). Drivers of Deforestation and Forest Degradation in Kilwa District, Mpingo Conservation \& Development Initiative, Lindi, Tanzania.

Nakai, K., Ishizuka, M., Ohta, S., Timothy, J., Jasper, M., Lyatura, N. M., Shau, V., and Yoshimura, T. (2019). "Environmental factors and wood qualities of African blackwood, Dalbergia melanoxylon, in Tanzanian Miombo natural forest," Journal of Wood Science 65(39), 1-11. DOI: 10.1186/s10086-019-1818-0

Ohmura, W., Doi, S., Aoyama, M., and Ohara, S. (2000). “Antifeedant activity of flavonoids and related compounds against the subterranean termite Coptotermes formosanus Shiraki," Journal of Wood Science 46(2), 149-153. DOI: 10.1007/BF00777362

Ohmura, W., Momohara, I., Kiguchi, M., Yoshimura, T., Takematsu, Y., Gensai, H., Nomura, T., Kaneda, T., Saegusa, M., Maeda, S., and Tanikawa, M. (2011). “Antitermite performance of Japanese and foreign timber species under different degradation environments," Mokuzai Gakkaishi 57(1), 26-33. (in Japanese) DOI: 10.2488/jwrs.57.26

Opulukwa, M. J., Hamza, K. F. S., and Malende, Y. H. M. B. (2002). "Inventory of Dalbegia melanoxylon (Mpingo) in the southern part of Tanzania: The case of Nachingwea," African Study Monographs 23(1), 1-10.

Reis, A. R. S., Reis, L. P., Júnior, M. A., de Carvalho, J. C., and da Silva, J. R. (2017). "Natural resistance of four Amazon woods submitted to xylophagous fungal infection under laboratory conditions," Madera y Bosques [Wood and Forests] 23(2), 155-162. DOI: $10.21829 /$ myb.2017.232968

Sacandé, M., Vautier, H., Sanon, M., and Schmit, L. (2007). Dalbergia Melanoxylon Guill. \& Perr (Seed Leaflet Report No. 135), University of Copenhagen, Copenhagen, Denmark.

Santana, A. L. B. D., Maranhão, C. A., Santos, J. C., Cunha, F. M., Conceiçāo, G. M., Bieber, L. W., and Nascimento, M. S. (2010). "Antitermitic activity of extractives from three Brazilian hardwoods against Nasutitermes corniger," International Biodeterioration \& Biodegradation 64(1), 7-12. DOI: 10.1016/j.ibiod.2009.07.009

Schultz, T. P., and Nicholas, D. D. (2000). "Naturally durable heartwood: Evidence for a proposed dual defensive function of the extractives," Phytochemistry 54(1), 47-52. DOI: 10.1016/s0031-9422(99)00622-6

Sekine, N., Ashitani, T., Murayama, T., Shibutani, S., Hattori, S., and Takahashi, K. (2009). "Bioactivity of latifolin and its derivatives against termites and fungi," Journal of Agricultural and Food Chemistry 57(13), 5707-5712. DOI: 10.1021/jf900719p

Seshadri, T. R. (1972). "Polyphenols of Pterocarpus and Dalbergia woods," Phytochemistry 11(3), 881-898. DOI: 10.1016/S0031-9422(00)88430-7

Sproßmann, R., Zauer, M., and Wagenführ, A. (2017). "Characterization of acoustic and mechanical properties of common tropical woods used in classical guitars," Results in Physics 7, 1737-1742. DOI: 10.1016/j.rinp.2017.05.006

Supriana, N. (1988). "Studies on the natural durability of tropical timbers to termite attack," International Biodeterioration 24(4-5), 337-341. DOI: 10.1016/02653036(88)90019-X

Tascioglu, C., Yalcin, M., Sen, S., and Akcay, C. (2013). “Antifungal properties of some plant extracts used as wood preservatives," International Biodeterioration \& Biodegradation 85, 23-28. DOI: 10.1016/j.ibiod.2013.06.004 
Usher, M. B., and Ocloo, J. K. (1975). "Testing the termite resistance of small, treated with water-borne preservatives wood blocks," Holzforschung 29(4), 147-151. DOI: 10.1515/hfsg.1975.29.4.147

White, F. (1983). "The Zambezian regional centre of endemism," in: The Vegetation of Africa: A Descriptive Memoir to Accompany the UNESCO/AETFAT/UNSO Vegetation Map of Africa, F. White (ed.), UNESCO, Paris, France, pp. 86-101.

Yin, X., Huang, A., Zhang, S., Liu, R., and Ma, F. (2018). "Identification of three Dalbergia species based on differences in extractive components," Molecules 23(9), 1-11. DOI: 10.3390/molecules23092163

Article submitted: December 26, 2019; Peer review completed: February 14, 2020;

Revised version received: March 5, 2020; Accepted: March 7, 2020; Published: March $13,2020$.

DOI: 10.15376/biores.15.2.2994-3005 